\title{
Static and Model Analysis on Pneumatic Suspension by using Ansys Software
}

\author{
Shaik Chand Mabhu Subhani ${ }^{1}$ I N.Vijay Kumar ${ }^{2}$
}

${ }^{1}$ Asst.professor, Department of Mechanical Engineering, Narasaraopeta Institute of Technology, Narasaraopet

${ }^{2}$ Assoc.professor, Department of Mechanical Engineering, Narasaraopeta Institute of Technology,Narasaraopet

To Cite this Article

Shaik Chand Mabhu Subhani and N.Vijay Kumar, "Static and Model Analysis on Pneumatic Suspension by using Ansys Software", International Journal for Modern Trends in Science and Technology, 6(12): 384-389, 2020.

\section{Article Info}

Received on 16-November-2020, Revised on 09-December-2020, Accepted on 12-December-2020, Published on 18-December-2020.

\section{ABSTRACT}

During the tractor movement, with being attached to the hitch-system working equipment over Rough road surfaces oscillation of the machine take place. These oscillations are a reason of pressure pulsations in the hydraulic hitch-system. The pressure pulse reduction in the tractor Hitch-system is important for increasing of the system components lifetime. Pressure oscillation damping in the tractor hydraulic hitch-system can reduce overall system oscillations and improve the driving control.

The design of spring in suspension system is very important. In this project a shock absorber is designed and a 3D model is created using CATIA V5 R20. The model is also changed by changing the thickness of the spring.

Structural analysis and modal analysis are done on the suspension system by varying material for spring, Spring Steel and Beryllium Copper. Analysis done in ANSYS 14.5. The analysis is done by considering loads, bike weight, single person and 2 persons. Structural analysis is done to validate the strength and modal analysis is done to determine the displacements for different frequencies for number of modes. Comparison is done for two materials to verify best material for spring in suspension system.

\section{KEYWORDS: pneumatic suspension, CATIA, FEA, Model analysis, static analysis.}

\section{INTRODUCTION}

Hydro pneumatic suspension is a type of motor vehicle suspension system, designed by Paul Mages, invented by Citroën, and fitted to Citroën cars, as well as being used under license by other car manufacturers, notably Rolls-Royce (Silver Shadow), Macerate and Peugeot. It was also used on Berlet trucks and has more recently been used on Mercedes- Benz cars. Similar systems are also used on some military vehicles. The suspension was referred to as oleopneumatique in early literature, pointing to oil and air as its main components. The purpose of this system is to provide a sensitive, dynamic and high-capacity suspension that offers superior ride quality on a variety of surfaces.

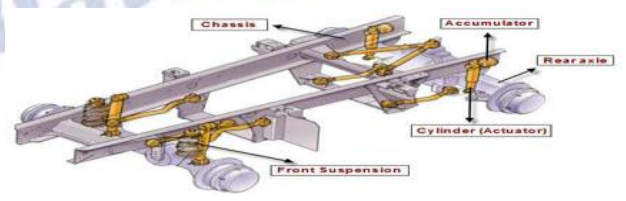

fig 1: hydro pneumatic suspension system

\subsection{Introduction to Catia}

Catia is the standard in 3D product design, featuring industry-leading productivity tools that promote best practices in design while ensuring 
compliance with your industry and company standards.

\subsection{Introduction to FEA}

FEA consists of a computer model of a material or design that is stressed and analyzed for specific results. It is used in new product design, and existing product refinement. A company is able to verify a proposed design will be able to perform to the client's specifications prior to manufacturing or construction. Modifying an existing product or structure is utilized to qualify the product or structure for a new service condition. In case of structural failure, FEA may be used to help determine the design modifications to meet the new condition. FEA uses a complex system of points called nodes which make a grid called a mesh. This mesh is programmed to contain the material and structural properties which define how the structure will react to certain loading conditions. Nodes are assigned at a certain density throughout the material depending on the anticipated stress levels of a particular area. In practice, a finite element analysis usually consists of three principal steps.

\subsection{Introduction to ANSYS}

ANSYS is general-purpose finite element analysis (FEA) software package. Finite Element Analysis is a numerical method of deconstructing a complex system into very small pieces (of user-designated size) called elements. The software implements equations that govern the behavior of these elements and solves them all; creating a comprehensive explanation of how the system acts as a whole. These results then can be presented in tabulated or graphical forms. This type of analysis is typically used for the design and optimization of a system far too complex to analyze by hand. Systems that may fit into this category are too complex due to their geometry, scale, or governing equations.

\section{Methodology}

Pneumatic suspension has been reviewed. Static and model analyses on the brake drum on different materials such as structural steel, Beryllium copper have been done.

The objectives of this study are:

To calculate the load $(\mathrm{kg})$, von-mises stress [mpa], von-mises strain, total deformation [mm] that is developed on Pneumatic suspension as materials structural steel, Beryllium copper.

To compare all the three results and conclude a best material for the selection of a Pneumatic suspension.

The steps involved in this methodology are

1. Model design

2. Meshing

3. Material Properties

4. Boundary condition

5. Results \& Discussion

\subsection{THE MODEL DESIGN}

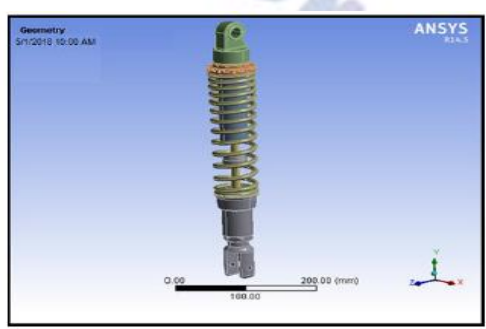

fig 2: imported model

A three-dimensional solid with shape and dimensions is modeled in catia. It is imported to ANSYS in igs formate.

\subsection{Meshed Model}

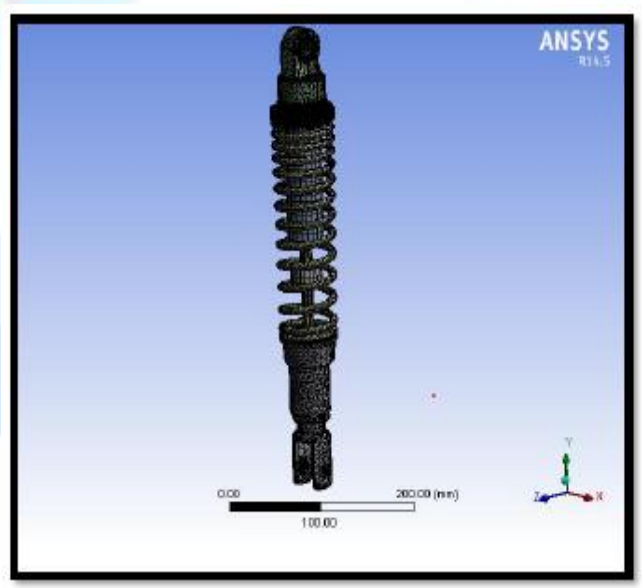

Fig.3 :Meshed Model

The elements used for the meshing of the full and ventilated disc are tetrahedral three-dimensional elements with nodes (iso-parametric). In this simulation, the meshing was refined in the contact zone (disc-pad). This is important because in this zone, the temperature varies significantly. Indeed, in this strongly deformed zone, the Thermo mechanical gradients 
are very high. This is why an accurate account of the contact conditions involve the use of a refined mesh. Three meshes have been tested automatically using an option called convergence in ANSYS Workbench Multi physics.

\subsection{Material Properties}

\section{Structural steel}

Density: $7850 \mathrm{~kg} / \mathrm{m} 3$

Ultimate Tensile Strength:

515-827Mpa

Yield Tensile Strength:

207-552Mpa

Young's Modulus:

190-210Gpa

Poisson's Ratio: 0.30

$\%$ of elongation: $12-40$

\section{Beryllium copper}

Density: $8260 \mathrm{Kg} / \mathrm{m} 3$

Ultimate Tensile Strength:

483-810Mpa

Yield Tensile Strength:

221-1172Mpa

Young's Modulus: 115Gpa

Poisson's Ratio: 0.30

Shear Modulus: 50Gpa

\section{RESUltS AND DISCUSSION}

\subsection{Static Structural Analysis by using ANSYS} R15

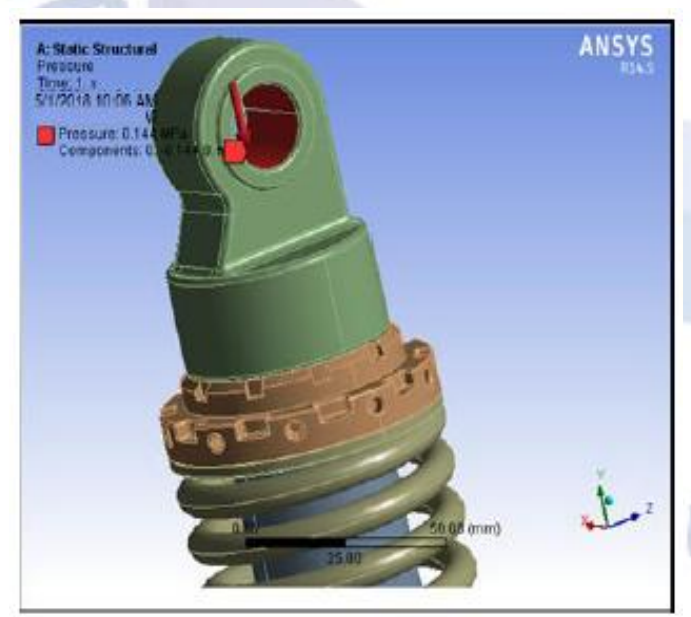

Fig 4: pressure on inner walls

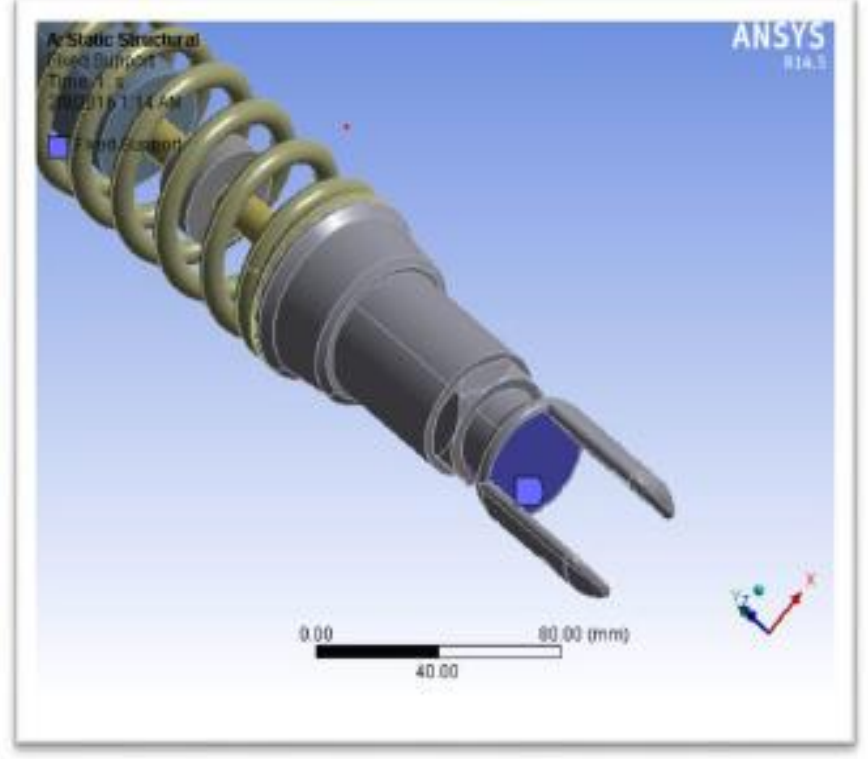

Fig 5: fixed support of Pneumatic suspension

\subsection{STRESS WITH I LOAD (113 KG)}

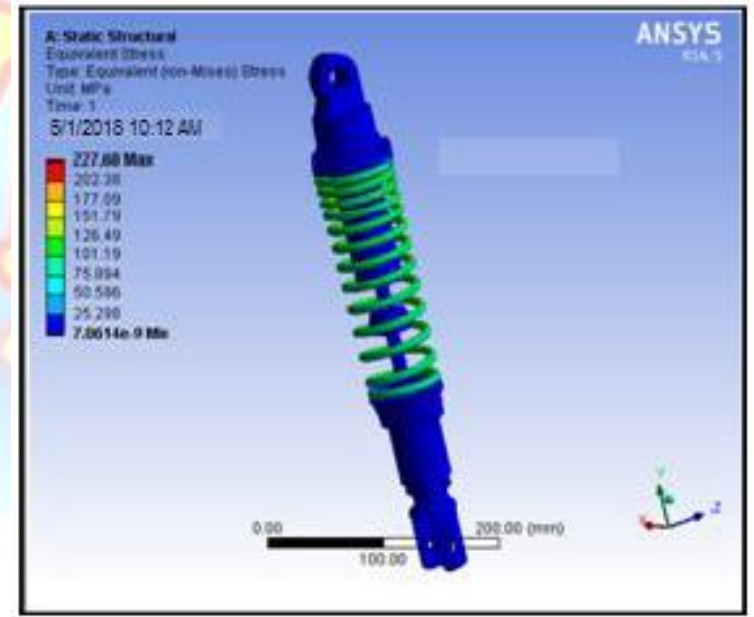

Fig 6: static structural equivalent stress

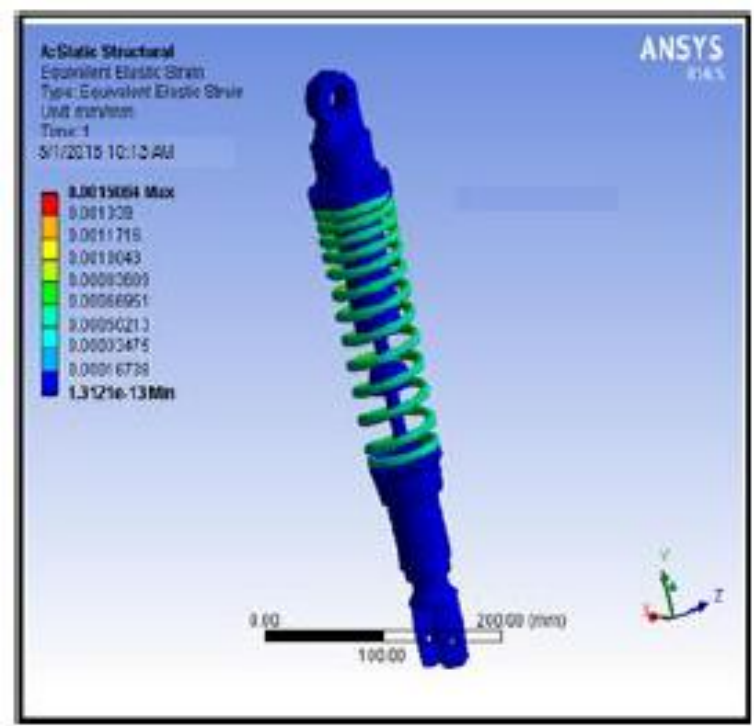

Fig 7: static structural equivalent elastic strains 


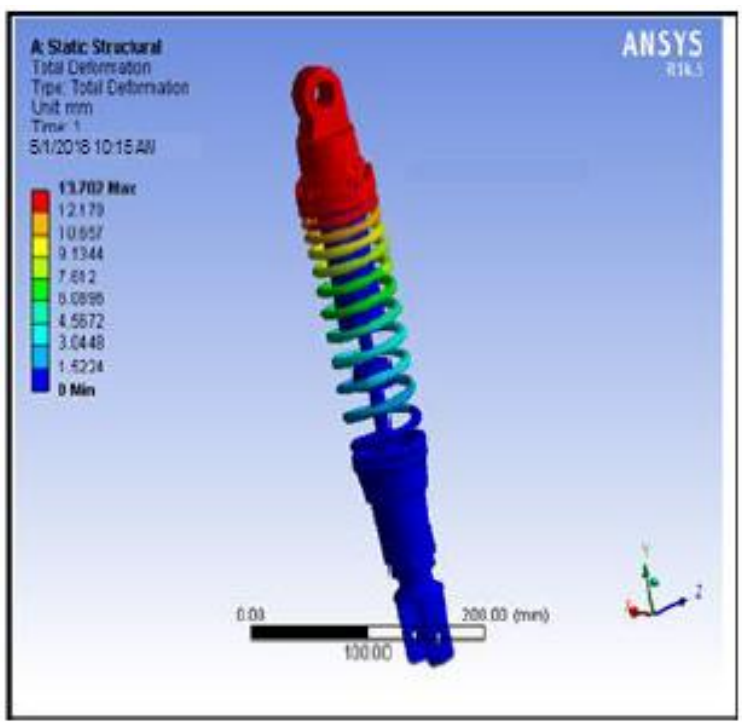

Fig 8: static structural total deformations 3.3 MODAL ANALYSIS OF HYDRO PNUMATIC SUSPENSION SYSTEM:

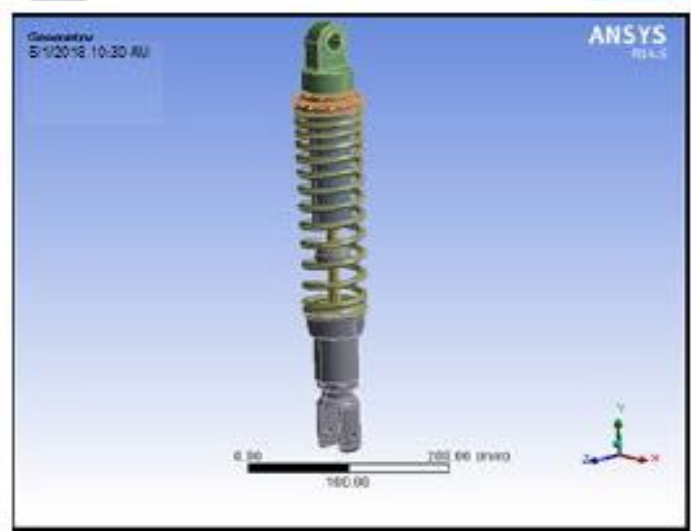

Fig 9: imported diagrams

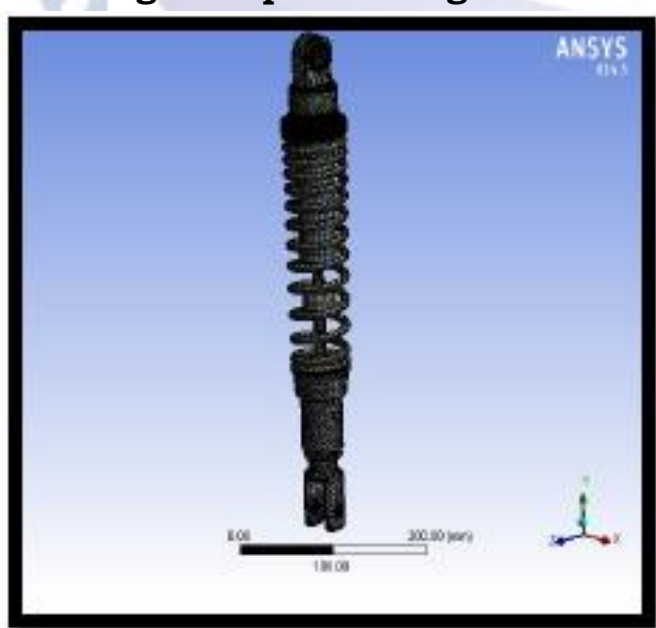

Fig 10: meshed model

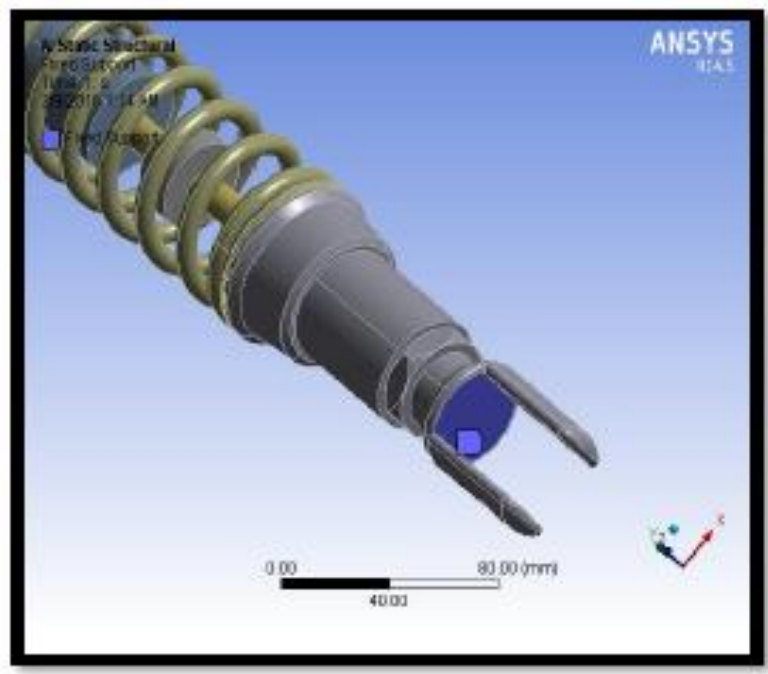

Fig 11: fixed supports

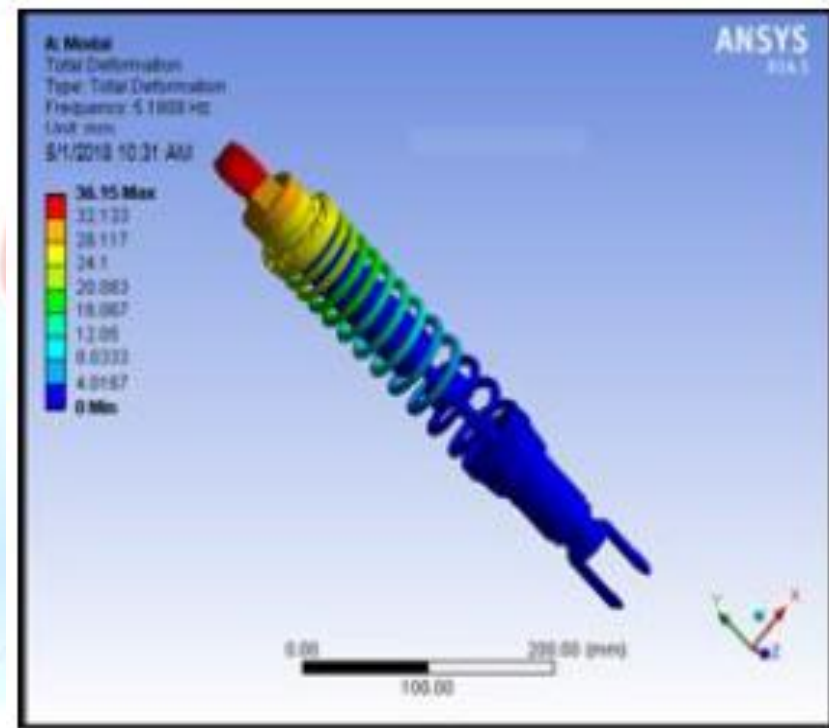

Fig 12: structural deformations 1

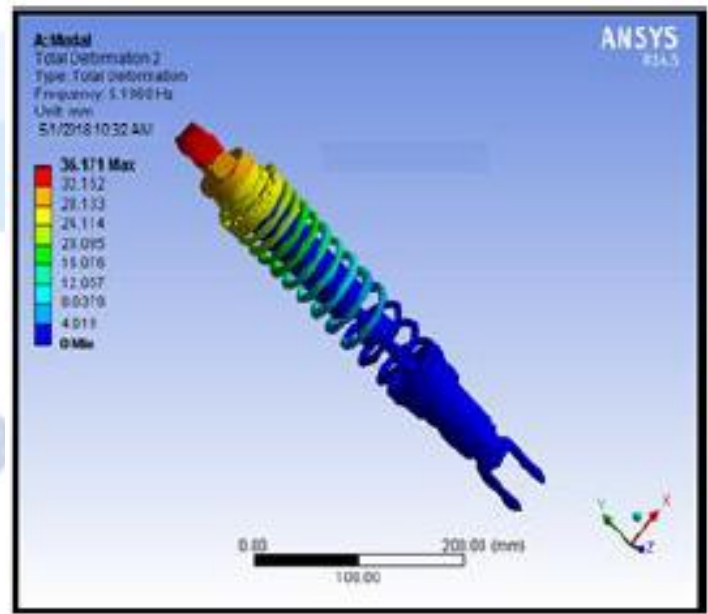

Fig 13: structural deformation 2 


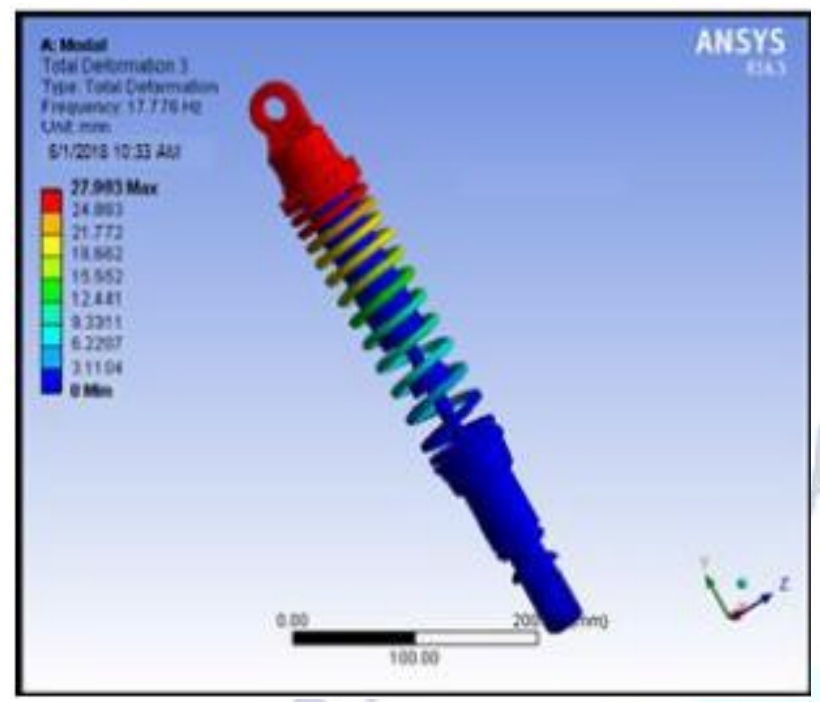

Fig 14: structural deformations 3

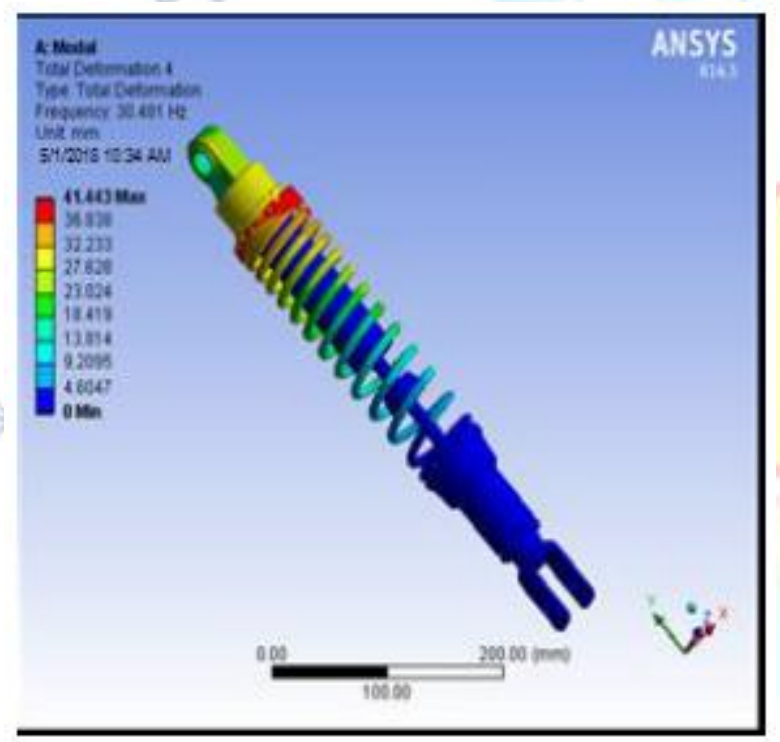

Fig 15: structural deformations 4

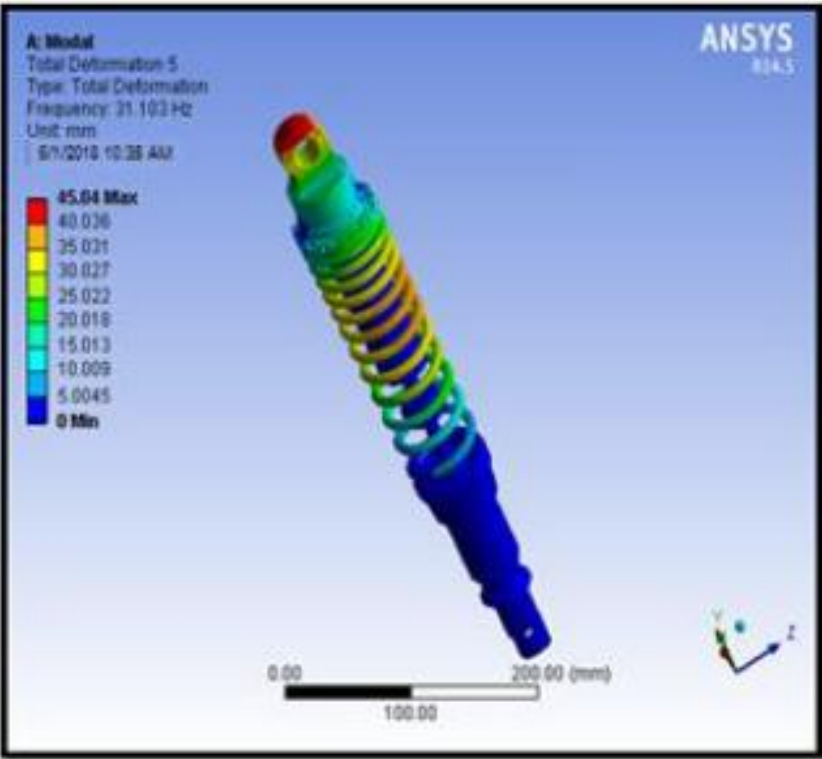

Fig 16: structural deformations 5

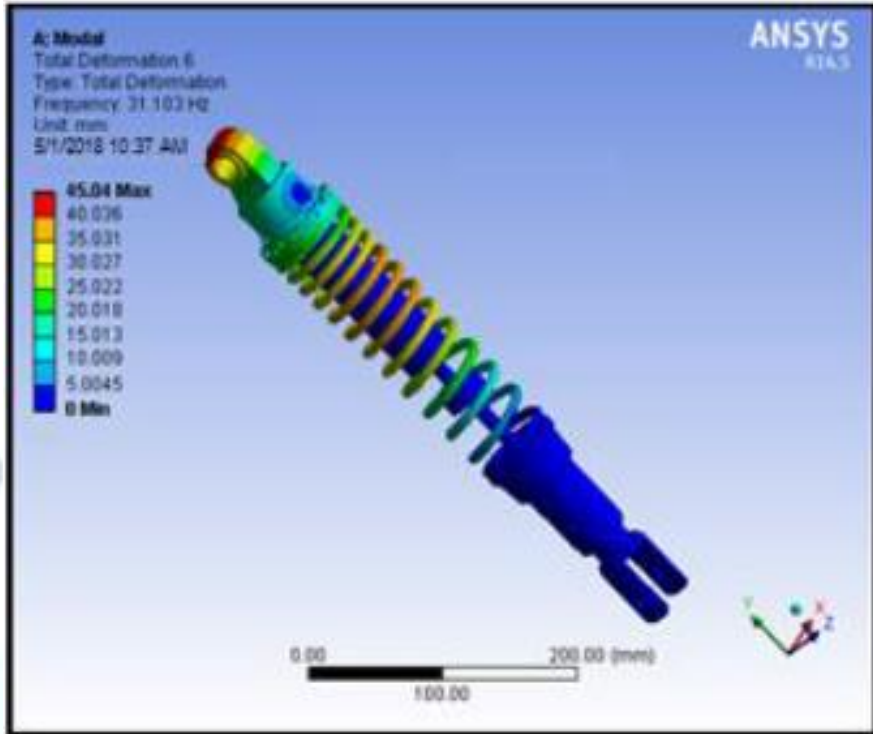

Fig 17: structural deformations 6

\subsection{RESULTS TABLE FOR STRUCTURAL} ANYLYSIS

\begin{tabular}{|c|c|c|c|c|}
\hline MATERIAL & $\begin{array}{c}\text { LOAD } \\
\text { (KG) }\end{array}$ & $\begin{array}{c}\text { VON-MISES } \\
\text { STRESS } \\
\text { [MPa] }\end{array}$ & $\begin{array}{l}\text { VON-MISES } \\
\text { STRAIN }\end{array}$ & $\begin{array}{c}\text { TOTAL } \\
\text { DEFORMATION } \\
{[\mathrm{mm}]}\end{array}$ \\
\hline \multirow{3}{*}{$\begin{array}{c}\text { Structural } \\
\text { steel }\end{array}$} & 113 & 227.68 & 0.0015 & 13.702 \\
\hline & 188 & 377.89 & 0.0025 & 22.741 \\
\hline & 263 & 529.68 & 0.0035 & 31.875 \\
\hline \multirow{3}{*}{$\begin{array}{c}\text { Beryllium } \\
\text { copper }\end{array}$} & 113 & 233.23 & 0.0026 & 23.794 \\
\hline & 188 & 387.1 & 0.0044 & 39.492 \\
\hline & 263 & 542.59 & 0.0062 & 55.355 \\
\hline
\end{tabular}

\subsection{RESULTS TABLE FOR MODAL ANALYSIS}

For Structural steel

\begin{tabular}{|c|c|c|}
\hline & $\begin{array}{c}\text { Deformation } \\
(\mathrm{mm})\end{array}$ & Frequency (Hz) \\
\hline Mode 1 & 36.15 & 5.1808 \\
\hline Mode 2 & 36.171 & 5.1969 \\
\hline Mode 3 & 27.993 & 17.776 \\
\hline Mode 4 & 41.443 & 30.481 \\
\hline
\end{tabular}




\begin{tabular}{|l|l|l|}
\hline Mode 5 & 45.04 & 31.103 \\
\hline
\end{tabular}

\section{For Beryllium copper}

\begin{tabular}{|c|c|c|}
\hline & $\begin{array}{c}\text { Deformation } \\
(\mathrm{mm})\end{array}$ & Frequency (Hz) \\
\hline Mode 1 & 35.241 & 3.8298 \\
\hline Mode 2 & 35.261 & 3.8417 \\
\hline Mode 3 & 27.29 & 13.14 \\
\hline Mode 4 & 40.401 & 22.532 \\
\hline Mode 5 & 44.397 & 22.847 \\
\hline
\end{tabular}

\section{CONCLUSION}

By observing the structural analysis results, the stress value is less for Beryllium Copper than Structural steel but the deformation is more.

By observing the modal analysis results, the deformation and frequency are less for Beryllium Copper than Structural Steel. Due to less frequency, the vibrations of suspension system when Beryllium Copper is used are less.

So it can be concluded that using Beryllium Copper is better.

\section{V.REFERENCES}

[1] Bernd Acker, Wolfgang Darenberg, and Heinz Gall. Active suspension for passenger cars. In IAVSD '89: Proceedings of the 11th Symposium of the International Association for Vehicle System Dynamics, pages 15-25, August 1989.

[2] Frank Frühauf and Rüdiger Rutz. Innovisia - an active suspension for a coach. Automatisierungstechnik, 46:120-127, March 1998.

[3] Michael Pyper, Wilhelm Schiffer, and Walter Schneider. ABC - Active Body Control. verlag moderne industrie / AG, Landsberg, Germany, 2003.

[4]. Magnus Rau. Modellierung, Simulation und Auslegung eines hydropneumatischen Federbeins mit schnell verstellbarer Dämpfung. Diplomarbeit, 2001.

[5] Jean-Jacques E. Slotine and Weiping Li. Applied Nonlinear Control. Prentice-Hall International, Inc., London, UK, 1991. 